\title{
Two Unexpected Temperature-Induced Supermolecular Isomers from Multi-Topic Carboxylic Acid: Hydrogen Bonding Layer or Helix Tube
}

\author{
Chunyang Li ${ }^{1}$, Chunhong Tan ${ }^{1}$, Juan Zhou ${ }^{1,2, *}$, Yan-Yong Lin ${ }^{3, *}$ and Xiao-Feng Wang ${ }^{1, *(D)}$ \\ 1 School of Chemistry and Chemical Engineering and Hunan Key Laboratory for the Design and Application of \\ Actinide Complexes, University of South China, Hengyang 421001, China; lcy4657857@sina.com (C.L.); \\ tanch2014@163.com (C.T.) \\ 2 School of Mechanical Engineering, University of South China, Hengyang 421001, China \\ 3 School of Chemistry and Chemical Engineering, Guangzhou University, Guangzhou 510006, China \\ * Correspondence: jzhouusc@126.com (J.Z.); linyy@gzhu.edu.cn (Y.-Y.L.); xfwang518@sina.cn (X.-F.W.)
}

Citation: Li, C.; Tan, C.; Zhou, J.; Lin, Y.-Y.; Wang, X.-F. Two Unexpected Temperature-Induced Supermolecular Isomers from Multi-Topic Carboxylic Acid: Hydrogen Bonding Layer or Helix Tube. Molecules 2021, 26, 6938. https: / / doi.org/10.3390/ molecules26226938

\section{Academic Editors: Marek}

Chmielewski, Patryk Niedbala and Maciej Majdecki

Received: 11 September 2021 Accepted: 12 November 2021 Published: 17 November 2021

Publisher's Note: MDPI stays neutral with regard to jurisdictional claims in published maps and institutional affiliations.

Copyright: (c) 2021 by the authors. Licensee MDPI, Basel, Switzerland. This article is an open access article distributed under the terms and conditions of the Creative Commons Attribution (CC BY) license (https:// creativecommons.org/licenses/by/ $4.0 /)$.

\begin{abstract}
Under ambient conditions or $160^{\circ} \mathrm{C}$, two supramolecular isomers, namely $\left[\left(\mathrm{H}_{4} \mathrm{PTTA}\right)\left(\mathrm{H}_{2} \mathrm{O}\right)_{2}\right.$ $(\mathrm{DMF})]$ and $\left[\left(\mathrm{H}_{4} \mathrm{PTTA}\right)\left(\mathrm{H}_{2} \mathrm{O}\right)_{3}\right] \cdot \cdot$ Guest (1-L and 1-H, $\mathrm{H}_{4}$ PTTA $=N$-phenyl- $N^{\prime}$-phenyl bicyclo[2.2.2] $]$ oct7-ene-2,3,5,6-tetracarboxdiimide tetra-carboxylic acid, Guest $=\mathrm{DMF}$ and $\mathrm{H}_{2} \mathrm{O}$ ), were obtained through the reaction of $\mathrm{H}_{4}$ PTTA in a mixture of $\mathrm{H}_{2} \mathrm{O}$ and dimethylformamide. The single crystal structures reveal the temperature-dependent supramolecular isomerism derived from the torsion of semi-rigid of $\mathrm{H}_{4}$ PTTA. The 1-L prepared at room temperature is a hydrogen bond based achiral layer, while the hydrothermal synthesized $\mathbf{1 - H}$ is isomer resulted in an H-bond-based chiral tubes-packed supramolecular framework.
\end{abstract}

Keywords: tetra-carboxylic acid; temperature-induced; hydrogen bonding; supramolecular isomeric; crystal structure

\section{Introduction}

Crystal engineering, traced since 1955 and accelerated in the 1980's by the independent efforts of Desiraju and other chemists, was further expanded as a fruitful research field encompassing various domains of chemistry, biology, pharmaceuticals and materials science [1-5]. In the last two decades, its development marks a shift from the analytical function of crystallography to the tuning of crystal structures, with the ultimate goal of the preparing of crystalline functional materials with promising properties [6-10]. In contrast to the hot topic branch of coordination polymers vial coordination bonds, the supramolecular synthesis for the preparation of new stable solid-state materials based on non-covalent interactions, which is the original research of crystal engineering, is still relatively obscure and should be strengthened.

One of the supramolecular fundamental principles is the consideration of intermolecular interactions between molecules in the same way as the covalent bonds connecting the atoms in the molecule [11]. Therefore, it is essential to understand the interactions of direct crystal packing and sustaining in order to assemble such supramolecular solids with the aid of different specific intermolecular contacts [12-14]. Besides aromatic stacking, hydrogen bonding frequently plays an overriding dominant factor in the rational design of supramolecular assemblies. For example, the prototypal organic networks of carboxylic acid systems are usually formed through the well-known $\mathrm{R}_{2}^{2}(8)$ eight-member carboxylic acid hydrogen bond dimers, which are considered as the concepts of supramolecular synthons [15]. Thus, the supramolecular synthon strategy has been widely applied to tailor co-crystals or supramolecular self-assemblies. Because of their strength and directionality, it is particularly useful when there are multiple functional groups capable of hydrogen bonding [16-18]. 
Generally, the role of hydrogen-bond synthons is now well established in supramolecular crystal engineering, and it can be categorized into two types: the homosynthons from self-complementary half units, and the heterosynthons consisting of two or more compo-

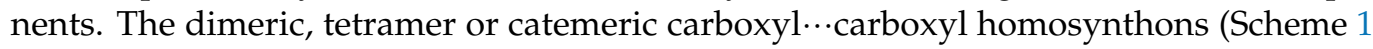
top) within the acid molecules dominate the interaction pattern for acid crystal structures [19-21]. Although the dimeric homosynthon acts as robust, it was demonstrated that it can be expanded or disrupted by the inclusion of water or alcohols (as both donor and acceptor), in order to be changed to the heterosynthons (one or two $\mathrm{H}_{2} \mathrm{O}$ symmetric inserting the dimmer, Scheme 1 bottom) involving - $\mathrm{COOH}$ and $-\mathrm{OH}$, and consequently can bring up structural uncertainty [22-24].
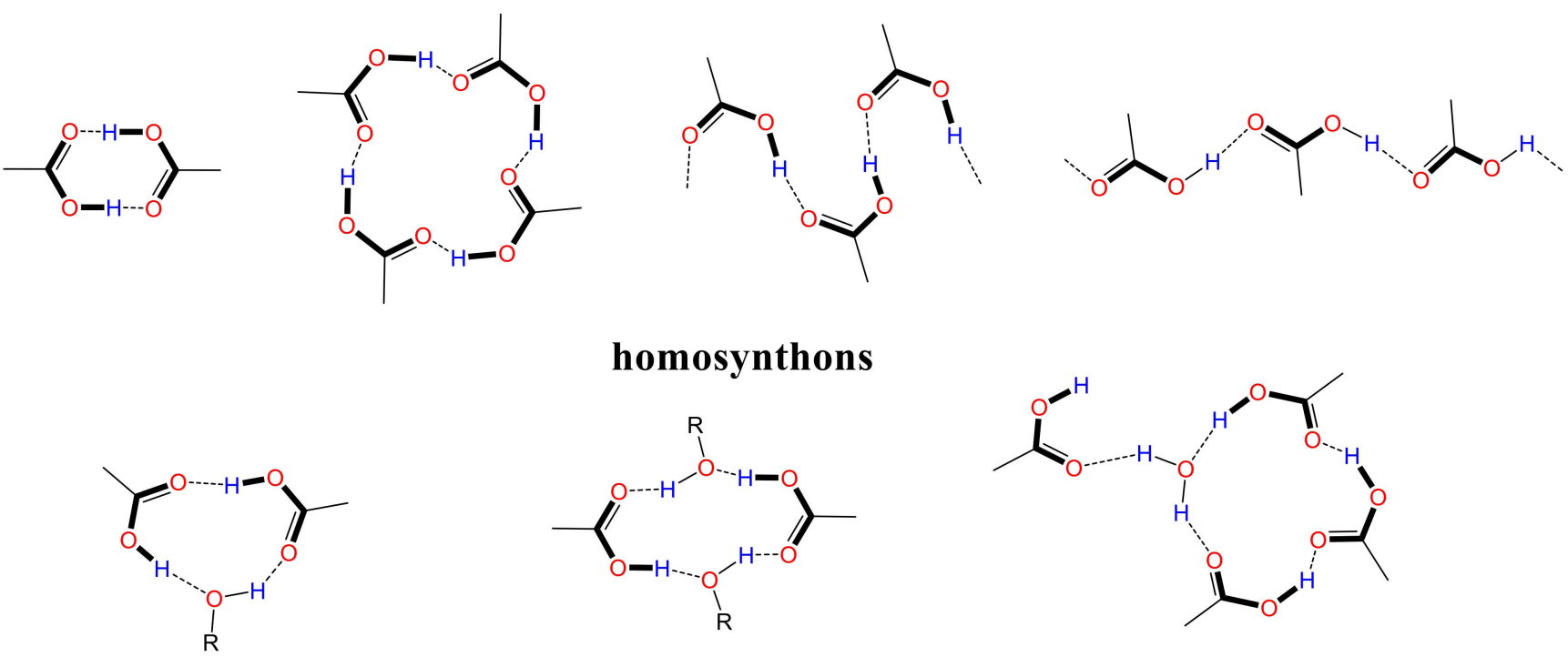

homosynthons
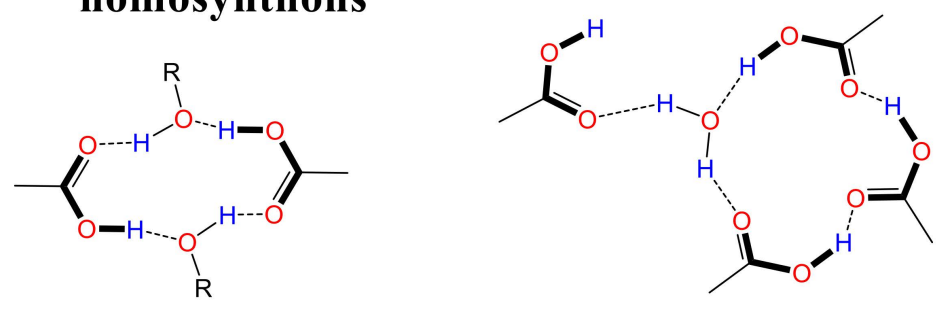

\section{heterosynthons}

Scheme 1. Supramolecular homosynthons (top) and heterosynthons (bottom).

The study of supramolecular isomerism is not only important in producing new materials but may also be helpful to fundamentally understanding the detail factors influencing the crystal growth process. Expected of co-crystals, the supramolecular isomerism, which comprises different structural networks derived from identical chemical compositions, is also attracting considerable investigative attentions. However, it is difficult and a great challenge to accurately predict or control the final supramolecular isomeric structures, owing to the subtle perturbation existence of thermodynamic and kinetic factors in the self-assembly process, such as different formation energy, building units' variation or intermolecular interactions. Although some temperature-induced isomeric coordination polymers have been reported $[25,26]$, the isomerism in a hydrogen bonding network is still rare $[27,28]$. Herein, we report two multitopic carboxylic acid-based isomers, where the solvent water molecules of solvation are incorporated, acting as the spacer characters to tune the homosynthon to heterosynthon, while being led to form the achiral layer at ambient or chiral tube at high temperature, respectively.

\section{Experimental Section}

\subsection{General Materials and Methods}

All the reagents and solvents were commercially available and used as received without further purification. The $\mathrm{C}, \mathrm{H}$ and $\mathrm{N}$ elemental analyses were carried out on a Vario EL elemental analyzer (Elementar, Hesse, Germany). The Raman spectrum was recorded on a Thermo Scientific DXR 3 spectrometer using KBr pellets (Waltham, MA, USA). ${ }^{1} \mathrm{H}$ liquid NMR spectrum was recorded with a Bruker AVANCE 300 spectrometer at 
300.13 MHz (Billerica, MA, USA). Circular dichroism (CD) spectra were measured on a Jasco J-810 CD instrument (Tokyo, Japan).

$N$-phenyl- $N$ '-phenyl bicyclo[2.2.2]oct-7-ene-2,3,5,6-tetracarboxdiimide tetracarboxylic acid $\left(\mathrm{H}_{4} \mathrm{PTTA}\right)$ was synthesized as described in the literature [29]: a mixture of 5-Aminoisophthalic acid (1.82 g, $10.05 \mathrm{mmol}$ ) and bicyclo[2.2.2]oct-7-ene-2,3,5,6-tetracarboxylic acid dianhydride (1.24 g, $5 \mathrm{mmol}$ ) in $N, N^{\prime}$-Dimethylformamide (DMF, $20 \mathrm{~mL}$ ) was refluxed for $12 \mathrm{~h}$ and then cooled down to room temperature. The yellow solution was poured into $500 \mathrm{~mL}$ deionized water and the $\mathrm{pH}$ was adjusted to 2 (with $5 \mathrm{M} \mathrm{HCl}$ ) to form a white suspension. White powder was filtrated, washed twice with water and dried under vacuum at $50{ }^{\circ} \mathrm{C}$ to remove the solvent water. Raman $(\mathrm{KBr})$ for $\mathrm{H}_{4}$ PTTA: $3086(\mathrm{~m}), 2960(\mathrm{~m}), 1782(\mathrm{~m}), 1609(\mathrm{~s})$, $1448(\mathrm{w}), 1391(\mathrm{~m}), 1306(\mathrm{w}), 1238(\mathrm{w}), 1179(\mathrm{~m}), 1089(\mathrm{~m}), 1056(\mathrm{w}), 1003(\mathrm{~s}), 940(\mathrm{w}), 837$ $(\mathrm{w}), 799(\mathrm{w}), 735(\mathrm{w}), 699(\mathrm{~m}), 634(\mathrm{~m}), 588(\mathrm{w}), 382(\mathrm{w}), 216(\mathrm{~s}), 112(\mathrm{~s}) \mathrm{cm}^{-1} .{ }^{1} \mathrm{H}$ NMR $(300$ MHz, DMSO) $\delta$ (ppm): 8.48(t, J = 14, 2H, ph), $7.99(\mathrm{~d}, \mathrm{~J}=14.6,4 \mathrm{H}, \mathrm{ph}), 6.44 \sim 6.41(\mathrm{~m}, 2 \mathrm{H}$, $-\mathrm{CH}=), 3.58(\mathrm{~s}, 2 \mathrm{H},-\mathrm{CH}), 3.50(\mathrm{~s}, 4 \mathrm{H},-\mathrm{CH})$. IR (KBr) for $\mathrm{H}_{4}$ PTTA: $3460(\mathrm{~s}, \mathrm{~b}), 1719$ (s), 1609 $(\mathrm{w}), 1459(\mathrm{~m}), 1383(\mathrm{~s}), 1308(\mathrm{w}), 1274(\mathrm{~m}), 1190(\mathrm{~s}), 1118(\mathrm{w}), 1083(\mathrm{w}), 1048(\mathrm{w}), 948(\mathrm{w})$, $793(\mathrm{~m}), 758(\mathrm{~m}), 682(\mathrm{~m}), 622(\mathrm{w}), 527(\mathrm{w}), 497(\mathrm{w})$ and $442(\mathrm{w}) \mathrm{cm}^{-1}$.

\subsubsection{Preparation of $\left[\left(\mathrm{H}_{4} \mathrm{PTTA}\right)\left(\mathrm{H}_{2} \mathrm{O}\right)_{2}(\mathrm{DMF})\right](\mathbf{1}-\mathrm{L})$}

To a solution of $\mathrm{H}_{4}$ PTTA $(0.162 \mathrm{~g}, 0.3 \mathrm{mmol})$ in DMF $(5 \mathrm{~mL})$ was added deionized water $(100 \mathrm{~mL})$, and then the $\mathrm{pH}$ value was adjusted to 2 using $2 \mathrm{M} \mathrm{HCl}$ dropwise under constant stirring for $30 \mathrm{~min}$. After filtered white precipitation, the clear filtrate was placed under ambient conditions; the colorless block-like crystals were isolated after slow evaporation of the solution in air for several weeks.

\subsubsection{Preparation of $\left[\left(\mathrm{H}_{4} \mathrm{PTTA}\right)\left(\mathrm{H}_{2} \mathrm{O}\right)_{3}\right] \cdot \cdot$ Guest $(\mathbf{1}-\mathrm{H})$}

$\mathrm{H}_{4}$ PTTA $(0.108 \mathrm{~g}, 0.2 \mathrm{mmol})$ was dissolved in a mixture of DMF $(15 \mathrm{~mL})$ and deionized water $(5 \mathrm{~mL})$ with constant stirring for $30 \mathrm{~min}$. The clear solution was heated at $160{ }^{\circ} \mathrm{C}$ for $72 \mathrm{~h}$ under autogeneous pressure in a $25 \mathrm{~mL}$ sealed Teflon-lined stainless-steel vessel. After autoclave cooling to room temperature at a rate of $5{ }^{\circ} \mathrm{C} \cdot \mathrm{h}^{-1}$, colorless block crystals were isolated.

\subsubsection{X-ray Crystallographic Analysis}

Single crystal data were collected on an Oxford CrysAlis CCD area detector diffractometer with graphite-monochromated $\mathrm{Cu}-\mathrm{K} \alpha$ radiation $(\lambda=1.54184 \AA)$ at $295(2) \mathrm{K}$. The structures were solved by direct methods and the subsequent difference Fourier synthesis was done using the SHELX-TL software suite [30]. Non-hydrogen atoms of the frameworks were refined anisotropically with hydrogen atoms generated as spheres riding the coordinates of their parent atoms. The solvent molecules in $\mathbf{1 - H}$ were highly disordered and were impossible to refine using conventional discrete-atom models; thus, the contribution of solvent electron density was removed by the SQUEEZE routine in PLATON [31]. The crystallographic data and structure determination parameters are given in Table 1, and selected bond lengths and angles in Table 2.

CCDC No. 2118337 and 2118346 contain the supplementary crystallographic data for the structures in this paper. These data can be obtained free of charge from the Cambridge Crystallographic Data Centre, CCDC, 12 Union Road, Cambridge CB2 1EZ, UK (Fax: +44-1223-336-033; or E-Mail: deposit@ccdc.cam.ac.uk, www.ccdc.cam.ac.uk, accessed on 11 September 2021). 
Table 1. The Crystallographic data for $\mathbf{1}-\mathbf{L}$ and $\mathbf{1}-\mathbf{H}^{\mathrm{a}}$.

\begin{tabular}{|c|c|c|}
\hline & $1-\mathrm{L}$ & $1-\mathrm{H}$ \\
\hline Empirical formula & $\mathrm{C}_{31} \mathrm{H}_{29} \mathrm{~N}_{3} \mathrm{O}_{15}$ & $\mathrm{C}_{28} \mathrm{H}_{24} \mathrm{~N}_{2} \mathrm{O}_{15}$ \\
\hline Formula weight & 683.59 & 628.49 \\
\hline Temperature & 293(2) & $296(2)$ \\
\hline Crystal system & Triclinic & Tetragonal \\
\hline Space group & $P-1$ & $P 4_{3} 22$ \\
\hline \multicolumn{3}{|l|}{ Unit cell dimensions } \\
\hline a $(\AA)$ & $7.0188(2)$ & $11.0795(2)$ \\
\hline $\mathrm{b}(\AA)$ & 13.4051(7) & $11.0795(2)$ \\
\hline$c(\AA)$ & 17.4948(8) & $35.0924(9)$ \\
\hline$\alpha /{ }^{\circ}$ & $101.590(4)$ & 90 \\
\hline$\beta /{ }^{\circ}$ & $98.090(3)$ & 90 \\
\hline$\gamma /{ }^{\circ}$ & $94.526(3)$ & 90 \\
\hline Volume $/ \AA^{3}$ & $1586.66(12)$ & $4307.78(19)$ \\
\hline Z & 2 & 4 \\
\hline$D_{\text {calc. }} / \mathrm{g} \cdot \mathrm{cm}^{-3}$ & 1.431 & 0.969 \\
\hline$\mu(\mathrm{MoK} \alpha) / \mathrm{mm}^{-1}$ & 0.994 & 0.080 \\
\hline$F(000)$ & 712 & 1304 \\
\hline$R_{\text {int }}$ & 0.019 & 0.080 \\
\hline Reflections collected & 9130 & 9844 \\
\hline Observed reflections $[I>2 \sigma(I)]$ & 4322 & 4446 \\
\hline Flack parameter & 0 & $0.1(16)$ \\
\hline Goodness-of-fit on $F^{2}$ & 1.05 & 1.12 \\
\hline$R_{1}[I>2 \sigma(I)]$ & 0.0457 & 0.0461 \\
\hline$w R_{2}$ (all data) & 0.1226 & 0.1365 \\
\hline Largest diff. peak and hole/e. $\AA^{-3}$ & 1.08 and -0.47 & 0.29 and -0.28 \\
\hline
\end{tabular}

${ }^{\mathrm{a}} R_{1}=\sum|| F_{\mathrm{o}}|-| F_{\mathrm{c}}|| / \sum\left|F_{\mathrm{o}}\right| \cdot w R_{2}=\left[\sum w\left(F_{\mathrm{o}}{ }^{2}-F_{\mathrm{c}}{ }^{2}\right)^{2} / \sum w\left(F_{\mathrm{o}}{ }^{2}\right)^{2}\right]^{1 / 2}$.

Table 2. Hydrogen bond parameters $\left(\AA,^{\circ}\right)$ in the crystal structures of $\mathbf{1 - L}$ and $\mathbf{1 - H}$.

\begin{tabular}{|c|c|c|c|c|}
\hline \multicolumn{5}{|c|}{ 1-L } \\
\hline $\mathrm{D}-\mathrm{H} \cdots \mathrm{A}$ & d(D-H) & $\mathbf{d}(\mathbf{H} \cdots \mathbf{A})$ & $d(D \cdots A)$ & $<$ (DHA) \\
\hline O1W-H1WA $\cdots$ O6 $^{\# 1}$ & 1.010 & 1.730 & $2.735(3)$ & 172 \\
\hline $\mathrm{O} 1 \mathrm{~W}-\mathrm{H} 1 \mathrm{WB} \cdots \mathrm{O} 2 \mathrm{~W}$ & 1.060 & 1.640 & $2.684(3)$ & 167 \\
\hline $\mathrm{O} 3-\mathrm{H} 3 \cdots \mathrm{O} 4^{\# 2}$ & 0.970 & 1.640 & $2.607(2)$ & 178 \\
\hline $\mathrm{O} 2 \mathrm{~W}-\mathrm{H} 2 \mathrm{WA} \cdots \mathrm{O} 13^{\# 3}$ & 0.890 & 1.880 & $2.768(4)$ & 171 \\
\hline $\mathrm{O} 2 \mathrm{~W}-\mathrm{H} 2 \mathrm{WB} \cdots \mathrm{O} 13^{\# 4}$ & 1.000 & 1.820 & $2.819(3)$ & 173 \\
\hline O5-H5 $\cdots$ O9 \#5 & 0.940 & 1.710 & $2.628(2)$ & 166 \\
\hline $\mathrm{O} 10-\mathrm{H} 10 \cdots \mathrm{O} 1 \mathrm{~W} \# 3$ & 0.990 & 1.520 & $2.506(3)$ & 173 \\
\hline $\mathrm{O} 12-\mathrm{H} 12 \cdots \mathrm{O} 11^{\# 6}$ & 1.050 & 1.560 & $2.593(2)$ & 168 \\
\hline 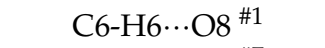 & 0.980 & 2.580 & $3.410(3)$ & 143 \\
\hline $\mathrm{C} 8-\mathrm{H} 8 \cdots \mathrm{O} 2^{\# 7}$ & 0.930 & 2.540 & $3.309(3)$ & 140 \\
\hline C31-H31B $\cdots \mathrm{O} 2{ }^{\# 7}$ & 0.960 & 2.510 & $3.366(4)$ & 148 \\
\hline \multicolumn{5}{|c|}{$\begin{aligned} \text { Symmetry codes: } \# 1=2-\mathrm{x}, 2-\mathrm{y}, 1-\mathrm{z} ; \# 2=1-\mathrm{x}, 2-\mathrm{y},-\mathrm{z} ; \# 3=-\mathrm{x}, 1-\mathrm{y}, 1-\mathrm{z} ; \# 4=1+\mathrm{x} \\
$\[ \mathrm{y}, 1+\mathrm{z} ; \# 5=2+\mathrm{x}, 1+\mathrm{y}, \mathrm{z} ; \# 6=1-\mathrm{x},-\mathrm{y}, 1-\mathrm{z} ; \# 7=-1+\mathrm{x}, \mathrm{y}, \mathrm{z} . \]$\end{aligned}$} \\
\hline \multicolumn{5}{|c|}{$1-\mathrm{H}$} \\
\hline D-H $\cdots A$ & d(D-H) & $\mathrm{d}(\mathrm{H} \cdots \mathbf{A})$ & $d(D \cdots A)$ & $<$ (DHA) \\
\hline $\mathrm{O} 2 \mathrm{~W}-\mathrm{H} 2 \mathrm{WA} \cdots \mathrm{O} 1^{\# 1}$ & 0.85 & 2.11 & $2.883(2)$ & 150 \\
\hline $\mathrm{O} 2 \mathrm{~W}-\mathrm{H} 2 \mathrm{WB} \cdots \mathrm{O} 4^{\# 2}$ & 0.85 & 1.95 & $2.784(3)$ & 167 \\
\hline $\mathrm{O} 2-\mathrm{H} 2 \mathrm{~A} \cdots \mathrm{O} 2{ }^{\# 3}$ & 0.86 & 1.6 & $2.440(2)$ & 164 \\
\hline $\mathrm{O} 3-\mathrm{H} 3 \cdots \mathrm{O} 2 \mathrm{~W}$ & 0.81 & 1.94 & $2.713(3)$ & 160 \\
\hline O1W-H1WA $\cdots$ O $2 W$ & 0.85 & 2.03 & $2.884(3)$ & 177 \\
\hline C3-H3A $\cdots 3^{\# 4}$ & 0.98 & 2.46 & $3.076(6)$ & 121 \\
\hline \multicolumn{5}{|c|}{$\begin{array}{l}\text { Symmetry codes: } \# 1=\mathrm{x}, 2-\mathrm{y}, 1 / 2-\mathrm{z} ; \# 2=-1+\mathrm{y}, 1+\mathrm{x}, 1 / 4-\mathrm{z} ; \# 3=\mathrm{x}, 1-\mathrm{y}, 1 / 2-\mathrm{z} \\
\qquad \begin{array}{l}\# 4=-1+\mathrm{y}, \mathrm{x}, 1 / 4-\mathrm{z}\end{array}\end{array}$} \\
\hline
\end{tabular}




\section{Results and Discussion}

\subsection{Structural Description of $\left[\left(\mathrm{H}_{4} \mathrm{PTTA}\right)\left(\mathrm{H}_{2} \mathrm{O}\right)_{2}(\mathrm{DMF})\right]$ (1-L)}

Solvates of $\mathrm{H}_{4}$ PTTA from a DMF/water mixture solution under an ambient condition, namely 1-L, gave high-quality crystals. As depicted in Figure 1, single crystal X-ray diffraction (SCXRD) shows that 1-L crystallizes in triclinic system with centrosymmetric space group P-1. An asymmetric unit contains one crystallographically tetra-carboxylic acid $\mathrm{H}_{4}$ PPTA molecule, two water molecules and one DMF molecule. The bicyclo[2.2.2]oct-2ene unit in the $\mathrm{H}_{4}$ PPTA is a boat-like conformation with the dihedral angle between pyrryl rings of $122.27^{\circ}$. The torsion angles between pyrryl and phenyl rings of isophthalic acid are $58.35^{\circ}$ and $51.84^{\circ}$, respectively. The two phenyl rings from isophthalic acid moieties rings are non-coplanar and form dihedral angles of $23.72^{\circ}$, while both planes defined by the - $\mathrm{COOH}$ group are almost coplanar with the dihedral angle of $3.60^{\circ}$. Within the $\mathrm{H}_{4} \mathrm{TPPA}$ molecule, there are two types of strong hydrogen bond motifs: $R_{2}^{2}(8)$ eight-member dimeric carboxylic homosynthon and one water inserted ten-member heterosynthon (Figure 1a). Each $\mathrm{H}_{4}$ TPPA features two homosynthons and two heterosynthons. Two $\mathrm{H}_{4}$ PTTAs combined with two isophthalic acid moieties from adjacent $\mathrm{H}_{4}$ PTTA to form two different apertures: dumbell and oval, respectively (Figure 1d,e), while one was fulfilled with lattice $\mathrm{H}_{2} \mathrm{O}$ and DMF molecules. Besides these conventional hydrogen bonds, there are two unconventional $\mathrm{C}-\mathrm{H} \cdots \mathrm{O}$ hydrogen bonds between the $-\mathrm{CH}_{3}$ from the DMF and $\mathrm{O}$ atoms from two kinds of groups (carboxyl and aldehyde group with the $\mathrm{C}-\mathrm{H} \cdots \mathrm{O}$ distances of $3.440 \AA$ and $3.366 \AA$, respectively), which are not only a steric effect but also play a significant role in the formation of supramolecular assembly. These acid moieties are linked via two kinds of H-bond synthons to form a 2-D herringbone pattern layer along [100] direction (Figure 2a). Furthermore, the adjacent 2-D layer arrays stack in an off-set mode along the (100) direction, holding via weak $\mathrm{C}-\mathrm{H} \cdots \mathrm{O}$ H-bonds between bicyclo[2.2.2]oct-2-ene unit and $\mathrm{O}$ atom from lattice water or pyrrolidine-2,5-dione segment to form a 3-D supramolecular structure. This suggests weak $\mathrm{C}-\mathrm{H} \cdots \mathrm{O}$ interaction forces consolidate the whole supramolecular system.

a)

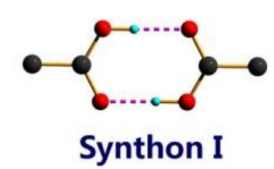

b)
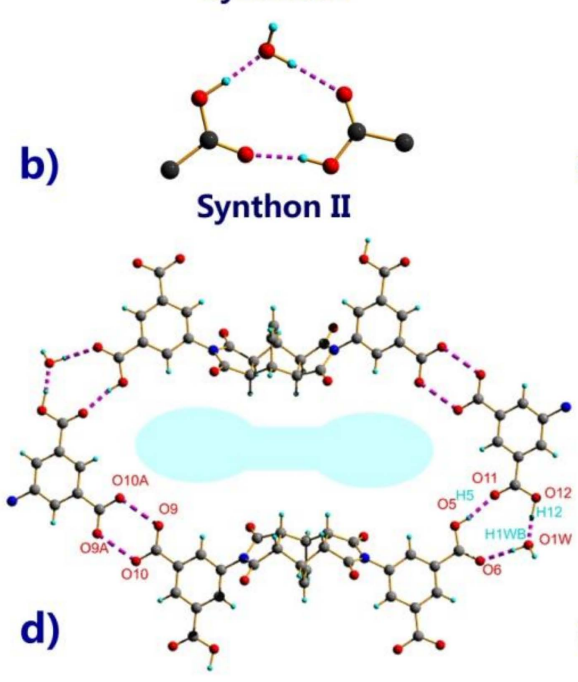

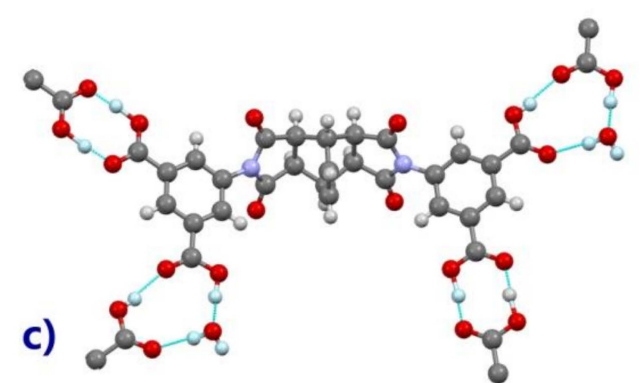

e)

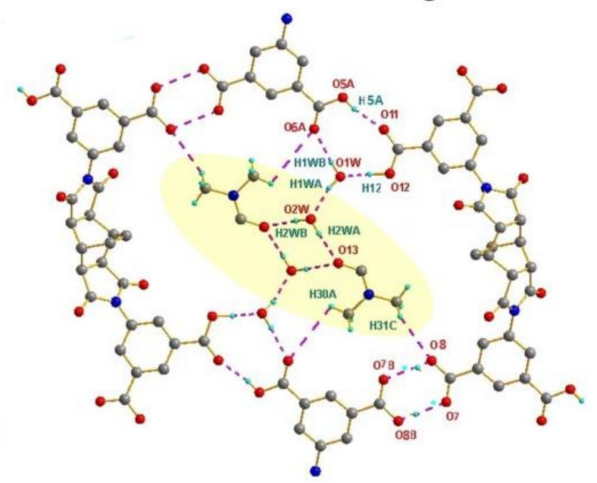

Figure 1. The homosynthon and heterosynthon (a,b); the H-bonds environment of one $\mathrm{H}_{4} \mathrm{PTTA}(\mathbf{c})$; two types of apertures: void (d) and fulfilled by lattice $\mathrm{H}_{2} \mathrm{O}$ and DMF (e) in 1-L. 


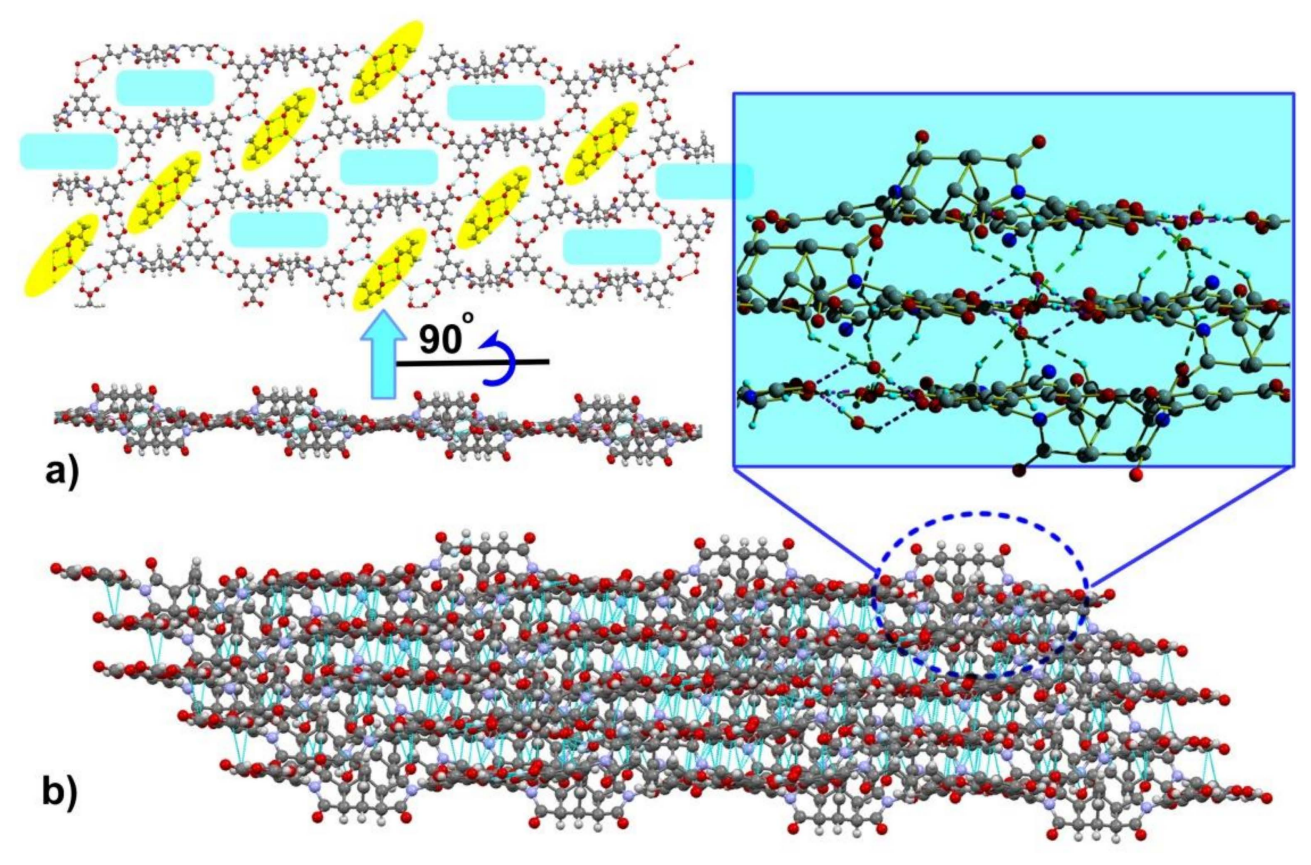

Figure 2. The top and side views of the two-dimensional hydrogen bond layer (a); the off-set packing of the two-dimensional hydrogen bonded sheets and interactions between adjacent layers (b) in 1-L.

\subsection{Structural Description of of $\left[\left(\mathrm{H}_{4} \mathrm{PTTA}\right)\left(\mathrm{H}_{2} \mathrm{O}\right)_{3}\right] \cdot \cdot$ Guest (1-H)}

Colorless block crystals can be obtained from DMF/water mixed solution at high temperature $\left(160^{\circ} \mathrm{C}\right)$, namely 1-H with guest molecules of DMF and $\mathrm{H}_{2} \mathrm{O}$. SCXRD shows that 1-H crystallizes in a tetragonal system with chiral space group $\mathrm{P}_{3} 22$. The asymmetric unit contains a half of a crystallographically tetra-carboxylic acid $\mathrm{H}_{4}$ PPTA molecule and one and a half water molecules. Similar to 1-L, the bicyclo[2.2.2] oct-2-ene unit center of the $\mathrm{H}_{4}$ PPTA molecule also adopted symmetric boat-like conformation, with a somewhat different dihedral angle between pyrryl rings of $123.68^{\circ}$. Within the $\mathrm{H}_{4}$ TPPA molecule, the angles between phenyl rings of isophthalic acid segments and pyrryl rings are both $65.70^{\circ}$. It is worth noting that the angle of the phenyl ring plane of the isophthalic acid is obviously different from that in $\mathbf{1 - L}$, which is $39.25^{\circ}$ larger than $23.72^{\circ}$. The two planes defined by the - $\mathrm{COOH}$ groups of the isophthalic acid segments are also non-coplanar with a dihedral angle of 4.93 or $16.59^{\circ}$, respectively. Each $\mathrm{H}_{4} \mathrm{TPPA}$ molecule holds eight hydrogen bonds featuring two kinds of $\mathrm{H}$-bond motifs: three water inserted 11-member heterosynthons, and one water inserted 7-member heterosynthon (Figure 3a,b, respectively). Notably, in the 11-member heterosynthon, the $\mathrm{H}_{2} \mathrm{O}$ molecules feature different roles: one $\mathrm{H}_{2} \mathrm{O}$ acting as two H-bond donors (O1W-H $\cdots \mathrm{O}, 2.884 \AA$ ), while another one acts as two H-bonds donors and two acceptors (O2W-H...O, 2.713, 2.784, 2.883 and $2.884 \AA$ A). Meanwhile, carboxylic groups act as $\mathrm{H}$-bond donors and acceptors with a chelate model. The $\mathrm{H}_{4}$ TPPA molecules are connected by these hydrogen bonds of two carboxylic acid groups: one is mode IV (Figure 3b), while another one is mode III (Figure 3a), in which the water molecule holds four hydrogen bonds as a bridge. In addition, the semi-rigid $\mathrm{H}_{4}$ TPPA molecule has a $\mathrm{C}-\mathrm{N}$ bond which can rotate with a certain angle, which hydrogen bonds combine together to construct a one-dimensional (1-D) infinite right-hand helix chain along the $b$-axis (see Figure 4a). Further, the adjacent 1-D chains array stack in an off-set mode along the $c$ axis to form right-hand helix tubes with a diameter of $18.22 \AA$, through intergral mode III and IV H-bond heterosynthons. The extended three-dimensional (3-D) homo-chiral supramolecular network with rhombic hydrophilic channels (fulfilled with guest molecules of DMF and $\mathrm{H}_{2} \mathrm{O}$ ) is eventually constructed via interlayer hydrogen bonds involving the lattice water and resting carboxyl of $\mathrm{H}_{4}$ TPPA tetra-acid (see Figure $4 \mathrm{~d}$ ). 


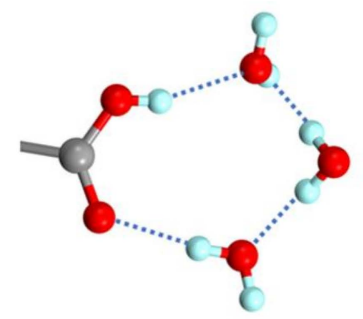

a) Synthon III

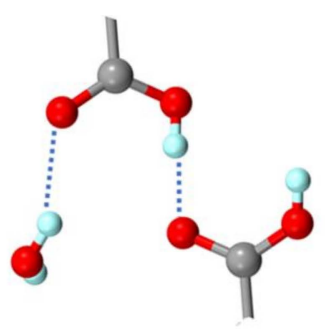

b) Synthon IV

c)

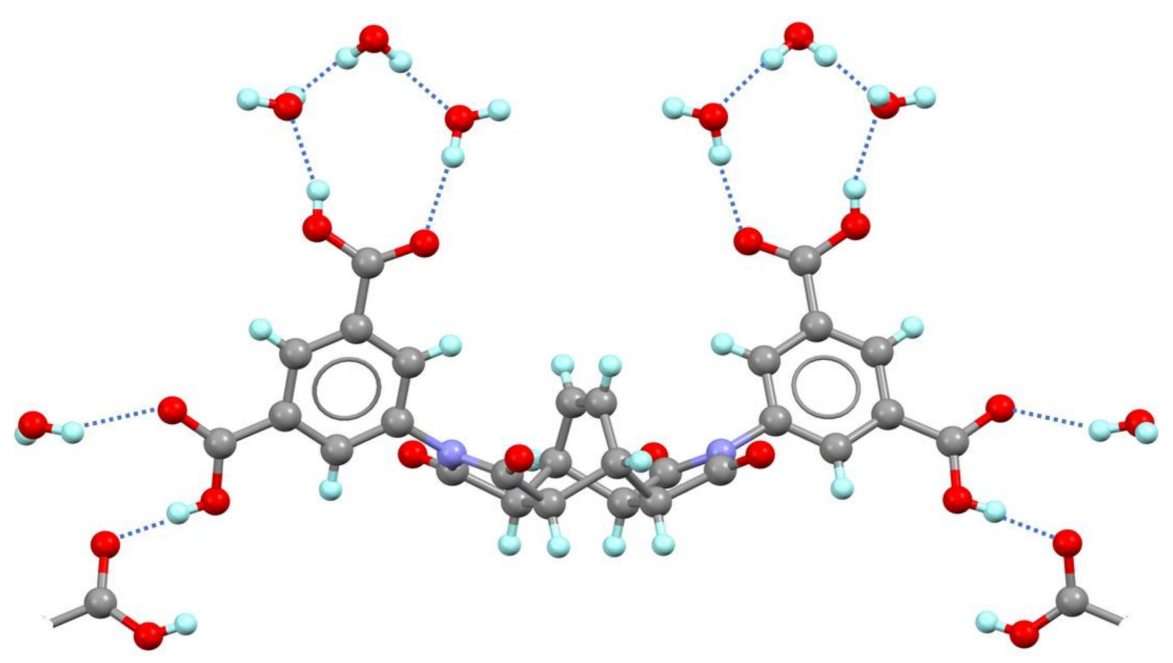

Figure 3. Two kinds of heterosynthons $(\mathbf{a}, \mathbf{b})$ and the H-bonds environment of one $\mathrm{H}_{4} \mathrm{PTTA}(\mathbf{c})$ in $\mathbf{1 - H}$.

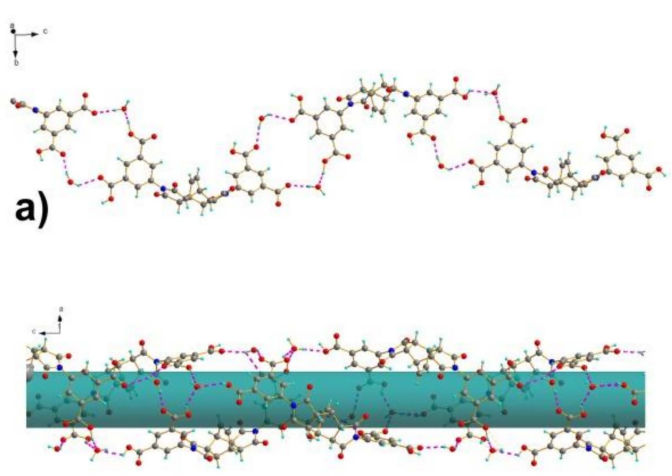

b) c)

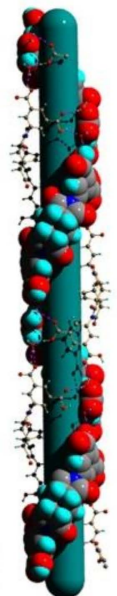

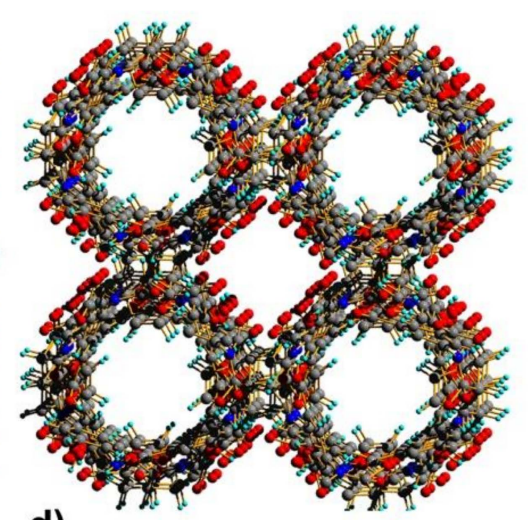

d)

Figure 4. The mono-helix H-bond chain layer (a); the bi-helix chains interacted chiral H-bond tube $(\mathbf{b}, \mathbf{c})$; the packing of the hydrogen bonded tubes $(\mathbf{d})$ in $\mathbf{1 - H}$.

\subsection{Syntheses and Structural Comparison}

Two isomeric supramolecular nets, 1-L and 1-H, built by tetra-acid are synthesized from the same starting reactants under different temperatures. Owing to its semi-rigid rotation of the $\mathrm{C}-\mathrm{N}$ bond, both phenyl rings of tetra-acid $\mathrm{H}_{4}$ TPPA adopt dissimilar orientations with the changed torsion angles from $51.84^{\circ}$ in $\mathbf{1 - L}$ to $65.70^{\circ}$ in $\mathbf{1 - H}$. The temperatureinduced configuration transformation of $\mathrm{H}_{4} \mathrm{TPPA}$ indicates that the structural variation in the final isomeric formed by H-bond frameworks (Scheme 2) is influenced by the temperature applied during the synthesis. Thus, H-bonded wave-layer 1-L is formed at the room 
temperature while the chiral H-bonded tube-like structure $\mathbf{1 - H}$ is constructed at $160{ }^{\circ} \mathrm{C}$ under hydrothermal conditions.

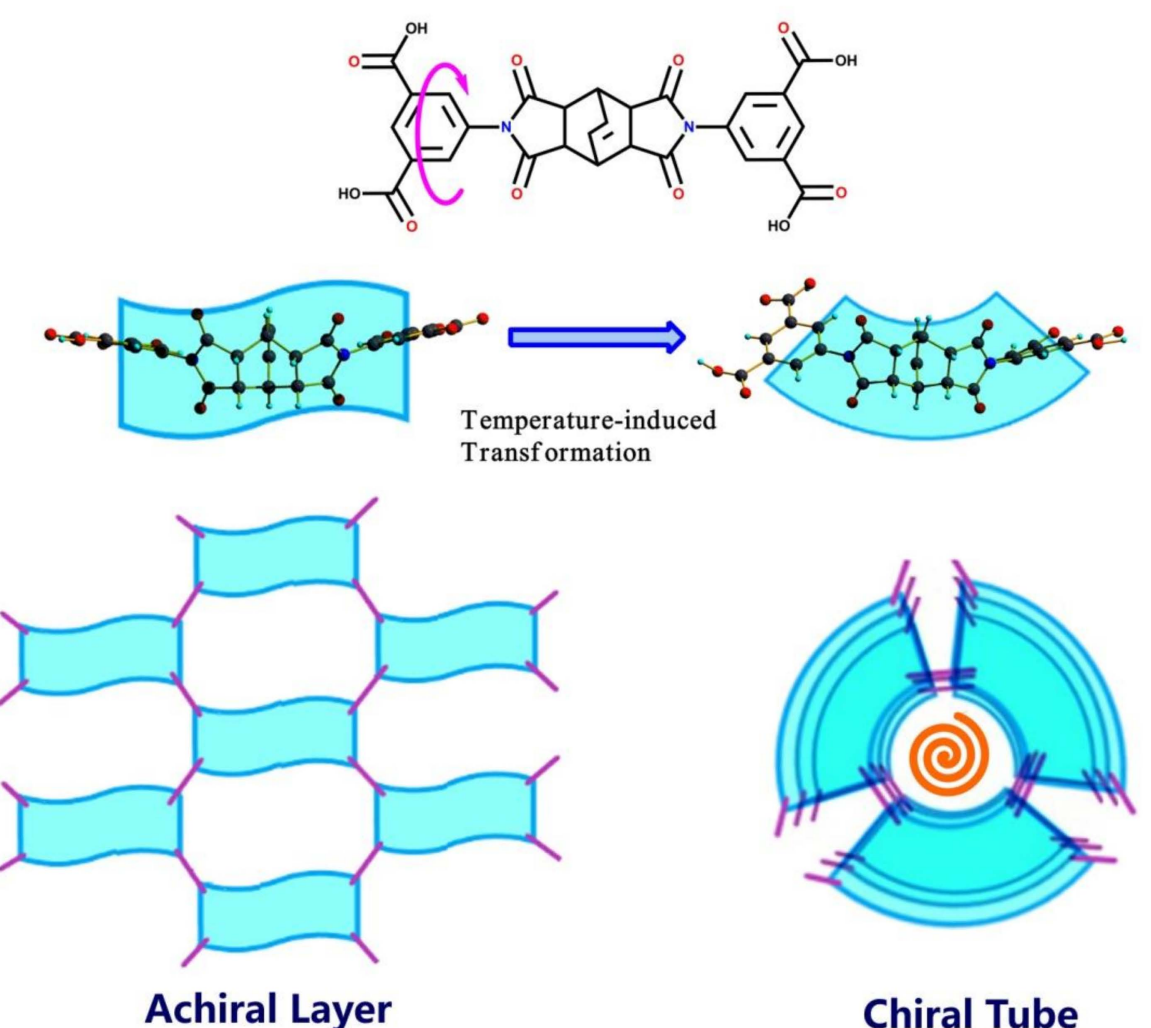

Scheme 2. The supramolecular isomeric transformation derived from the ip segments torsion of semi-rigid tetra-acid ligands.

\subsection{Spectroscopy}

Analysis of the crystal structure suggests that $\mathbf{1 - H}$ is a chiral supramolecular organic framework [32], which entails the self-assembly of homo-chiral (right-helix) tubes derived from the achiral semi-rigid tetra-acids being assembled via different hydrogen bond motifs. It has been confirmed in a kinetic model that an achiral artificial assembly system could spontaneously produce chirality [33]. However, without inducing the chiral chemical regents (as reactants or template), the coordinated or covalent enantiomers are commonly observed in the spontaneous resolution system [34-37]. Although 1-H should contain two different enantiomer single crystals, unfortunately, the attempt to pick out and solve the left-helix structure of single-crystal X-ray crystallography failed. However, the circular dichroism (CD) measurement based on more than 50 randomly picked crystals from onepot resulted in solid CD spectroscopy, showing that $\mathbf{1 - H}$ explicitly exhibits Cotton effects at about $\lambda=215$ and $255 \mathrm{~nm}$, which confirms that the right- and left-helix enantiomers were spontaneously resoluted during the course of the crystallization in the one-pot hydrothermal reaction, as shown in Figure 5. The results indicate that more research into the rational syntheses strategy is required in order to figure out how to control the preparation of the homo-chiral H-bonded frameworks from spontaneous resolution. 


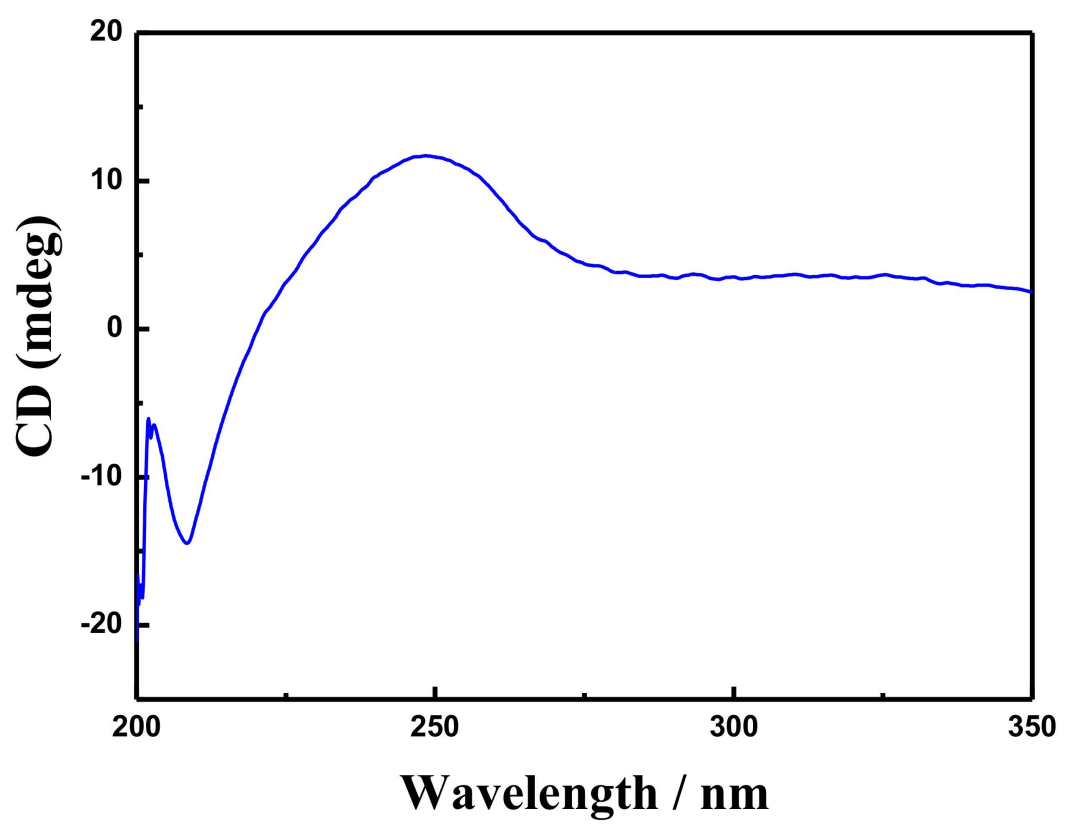

Figure 5. The solid-state circular dichroism (CD) spectra of stochastic of conglomerate 1-H.

\section{Conclusions}

In this work, we have successfully synthesized two supramolecular compounds, namely 1-L and 1-H, starting from the same precursors, the mixture of semi-rigid tetra-acid $\mathrm{H}_{4}$ TPPA, $\mathrm{H}_{2} \mathrm{O}$ and DMF. It is interesting that both supramolecular compounds performed variable hydrogen bond isomers under different synthesis temperatures. The room temperature approach leads to the formation of $\mathbf{1 - L}$, which features the H-bond layer structure based on the general dimeric homosynthon and one $\mathrm{H}_{2} \mathrm{O}$ inserted dimmeric heterosynthon. 1-H synthesized at $160^{\circ} \mathrm{C}$ under hydrothermal conditions, and results in the chiral $\mathrm{H}$-bonded tube were based on two kinds of $\mathrm{H}$-bond heterosynthons. Notably, the structural differences between two supramolecular isomers of 1-L and 1-H were derived from the rotation of the $\mathrm{C}-\mathrm{N}$ bond of semi-rigid tetra-acid $\mathrm{H}_{4}$ TPPA, which induced the different torsion of both isophthalic acid segments within $\mathrm{H}_{4}$ TPPA.

Author Contributions: Conceptualization, J.Z., Y.-Y.L. and X.-F.W.; methodology, C.L. and X.-F.W.; software, C.T., Y.-Y.L. and X.-F.W.; validation, C.T. and X.-F.W.; formal analysis, Y.-Y.L. and X.-F.W.; investigation, J.Z., Y.-Y.L. and X.-F.W.; resources, X.-F.W.; data curation, C.L., C.T. and J.Z.; writingoriginal draft preparation, Y.-Y.L. and X.-F.W.; writing-review and editing, Y.-Y.L. and X.-F.W.; visualization, X.-F.W.; supervision, X.-F.W.; project administration, X.-F.W.; funding acquisition, J.Z., C.T. and X.-F.W. All authors have read and agreed to the published version of the manuscript.

Funding: This research was supported by Hunan Provincial Natural Science Foundation of China (grant number 2021JJ30565, 2020JJ5473 and 2019JJ50524), We wish to thank the financial support from University of South China (No. 2015XQD53).

Institutional Review Board Statement: Not applicable.

Informed Consent Statement: Not applicable.

Data Availability Statement: Crystallographic data for (1-L and 1-H) have been deposited with the Cambridge Crystallographic Data Center as supplemental publication numbers CCDC No. 2118337 and 2118346, respectively. Copies of the data can be obtained free of charge via http:/ /www.ccdc.cam.ac.uk/ data_request/cif, (accessed on 11 September 2021), or by emailing data_request@ccdc.cam.ac.uk, or by contacting The Cambridge Crystallographic Data Centre, 12, Union Road, Cambridge CB2 1EZ, UK.

Conflicts of Interest: The authors declare no conflict of interest.

Sample Availability: Samples of the compounds are not available from the authors. 


\section{References}

1. Pepinsky, R. Crystal engineering: New concept in crystallography. Phys. Rev. 1955, 100, 971.

2. Desiraju, G.R. Crystal Engineering: The Design of Organic Solids; Elsevier: Amsterdam, the Netherlands, 1989.

3. Desiraju, G.R. Crystal Engineering: A Holistic View. Angew. Chem. Int. Ed. 2007, 46, 8342-8356. [CrossRef] [PubMed]

4. Brammer, L. Developments in inorganic crystal engineering. Chem. Soc. Rev. 2004, 33, 476-489. [CrossRef] [PubMed]

5. Duggirala, N.K.; Perry, M.L.; Almarsson, Ö.; Zaworotko, M.J. Pharmaceutical cocrystals: Along the path to improved medicines. Chem. Commun. 2016, 52, 640-655. [CrossRef]

6. Yaghi, O.M.; O'Keeffe, M.; Ockwig, N.W.; Chae, H.K.; Eddaoudi, M.; Kim, J. Reticular Synthesis and the Design of New Materials. Nature 2003, 423, 705-714. [CrossRef]

7. Braga, D.; Brammer, L.; Champness, N.R. New trends in crystal engineering. CrystEngComm 2005, 7, 1-19. [CrossRef]

8. Hosseini, M.W. Molecular tectonics: From simple tectons to complex molecular networks. Acc. Chem. Res. 2005, 38, 313-323. [CrossRef]

9. Sasaki, T.; Sakamoto, S.; Takamizawa, S. Organoferroelastic Crystal Prepared by Supramolecular Synthesis. Cryst. Growth Des. 2020, 20, 1935-1939. [CrossRef]

10. Lin, R.B.; He, Y.; Li, P.; Wang, H.; Zhou, W.; Chen, B. Multifunctional Porous Hydrogen-Bonded Organic Framework Materials. Chem. Soc. Rev. 2019, 48, 1362-1389. [CrossRef]

11. Lehn, J.-M. From supramolecular chemistry towards constitutional dynamic chemistry and adaptive chemistry. Chem. Soc. Rev. 2007, 36, 151-160. [CrossRef]

12. Bis, J.A.; McLaughlin, O.L.; Vishweshwar, P.; Zaworotko, M.J. Supramolecular heterocatemers and their role in cocrystal design. Cryst. Growth Des. 2006, 6, 2648-2650. [CrossRef]

13. Aakeröy, C.B.; Beatty, A.M.; Helfrich, B.A. "Total synthesis" supramolecular style: Design and hydrogen-bond-directed assembly of ternary supermolecules. Angew. Chem. Int. Ed. 2001, 40, 3240-3242. [CrossRef]

14. Sokolov, A.N.; Friscic, T.; MacGillivray, L.R. Enforced face-to-face stacking of organic semiconductor building blocks within hydrogen-bonded molecular cocrystals. J. Am. Chem. Soc. 2006, 128, 2806-2807. [CrossRef] [PubMed]

15. Desiraju, G.R. Supramolecular synthons in crystal engineering-a new organic synthesis. Angew. Chem. Int. Ed. 1995, 34, $2311-2327$. [CrossRef]

16. Joanna, A.B.; Vishweshwar, P.; Weyna, D.; Zaworotko, M.J. Hierarchy of supramolecular synthons: Persistent hydroxyl $\cdots$ pyridine hydrogen bonds in cocrystals that contain a cyano acceptor. Mol. Pharm. 2007, 4, 401-416.

17. Rajput, L.; Biradha, K. Design of cocrystals via new and robust supramolecular synthon between carboxylic acid and secondary amide: Honeycomb network with jailed aromatics. Cryst. Growth Des. 2009, 9, 40-42. [CrossRef]

18. Wang, L.; Xu, L.Y.; Xue, R.F.; Lu, X.F.; Chen, R.X.; Tao, X.T. Cocrystallization of N-donor type compounds with 5-sulfosalicylic acid: The effect of hydrogen-bonding supramolecular architectures. Sci. China Chem. 2012, 55, 138-144. [CrossRef]

19. Kanters, J.A.; Roelofsen, G. Hydrogen-Bond Motifs of Carboxylic Acids: The $\alpha$-Form of Monochloroacetic Acid. Acta Cryst. B 1976, 32, 3328-3331. [CrossRef]

20. Kanters, J.A.; Roelofsen, G.; Feenstra, T. Hydrogen-Bond Motifs of Carboxylic Acids: The $\beta$-Form of Monochloroacetic Acid. Acta Cryst. B 1976, 32, 3331-3333. [CrossRef]

21. Leiserowitz, L. Molecular Packing Modes. Carboxylic Acids. Acta Cryst. B 1976, 32, 775-802. [CrossRef]

22. Rajput, L.; Jana, N.; Biradha, K. Carboxylic Acid and Phenolic Hydroxyl Interactions in the Crystal Structures of CoCrystals/Clathrates of Trimesic Acid and Pyromellitic Acid with Phenolic Derivatives. Cryst. Growth Des. 2010, 10, 4565-4570. [CrossRef]

23. D'Ascenzo, L.; Auffinger, P. A comprehensive classification and nomenclature of carboxyl-carboxyl(ate) supramolecular motifs and related catemers: Implications for biomolecular systems. Acta Cryst. B 2015, 71, 164-175. [CrossRef]

24. Ou, G.; Wang, Q.; Zhou, Q.; Wang, X.-F. Phenol Derivatives as Co-Crystallized Templates to Modulate Trimesic-Acid-Based Hydrogen-Bonded Organic Molecular Frameworks. Crystals 2021, 11, 409. [CrossRef]

25. Wang, X.-F.; Zhang, Y.-B.; Xue, W.; Qi, X.-L.; Chen, X.-M. Two temperature-induced isomers of metal-carboxylate frameworks based on different linear trinuclear $\mathrm{Co}_{3}(\mathrm{RCOO})_{8}$ clusters exhibiting different magnetic behaviours. CrystEngComm 2010, 12, 3834-3839. [CrossRef]

26. Du, L.-Y.; Shi, W.-J.; Hou, L.; Wang, Y.-Y.; Shi, Q.-Z.; Zhu, Z. Solvent or Temperature Induced Diverse Coordination Polymers of Silver(I) Sulfate and Bipyrazole Systems: Syntheses, Crystal Structures, Luminescence, and Sorption Properties. Inorg. Chem. 2013, 52, 14018-14027. [CrossRef]

27. Moulton, B.; Zaworotko, M.J. From molecules to crystal engineering: Supramolecular isomerism and polymorphism in network solids. Chem. Rev. 2001, 101, 1629-1658. [CrossRef]

28. Bhattacharya, S.; Saha, B.K. Guest-induced isomerization of net and polymorphism in trimesic acid-arylamine complexes. Cryst. Growth Des. 2011, 11, 2194-2204. [CrossRef]

29. Wang, X.-F.; Chen, Y.; Song, L.-P.; Fang, Z.; Zhang, J.; Shi, F.; Lin, Y.-W.; Sun, Y.; Zhang, Y.-B.; Rocha, J. Cooperative Capture of Uranyl Ions by a Carbonyl-Bearing Hierarchical-Porous Cu-Organic Framework. Angew. Chem. Int. Ed. 2019, 58, 18808-18812. [CrossRef] [PubMed]

30. Sheldrick, G.M. Crystal structure refinement with SHELXL. Acta Cryst. A 2015, 71, 3-8. [CrossRef]

31. Spek, A.L.J. Single-crystal structure validation with the program PLATON. Appl. Crystallogr. 2003, 36, 7. [CrossRef] 
32. Li, Y.; Li, Q.; Miao, X.; Qin, C.; Chu, D.; Cao, L. Adaptive Chirality of an Achiral Cucurbit[8]uril-Based Supramolecular Organic Framework for Chirality Induction in Water. Angew. Chem. Int. Ed. 2021, 60, 6744-6751. [CrossRef]

33. Frank, F.C. On spontaneous asymmetric synthesis. Biochim. Biophys. Acta 1953, 11, 459-463. [CrossRef]

34. Chen, Y.; Tan, C.; Song, L.-P.; Zhou, J.; Zeng, Q.; Xie, R.; Wang, X.-F. Two chiral cadmium carboxylate framework isomers generated by spontaneous resolution: Synthesis, structures and properties. J. Coord. Chem. 2019, 72, 251-261. [CrossRef]

35. Wu, D.; Zhou, K.; Tian, J.; Liu, C.; Tian, J.; Jiang, F.; Yuan, D.; Zhang, J.; Chen, Q.; Hong, M. Induction of Chirality in a Metal-Organic Framework Built from Achiral Precursors. Angew. Chem. Int. Ed. 2021, 60, 3087-3094. [CrossRef] [PubMed]

36. Roszak, K.; Katrusiak, A. High-pressure and temperature dependence of the spontaneous resolution of 1,1'-binaphthyl enantiomers. Phys. Chem. Chem. Phys. 2018, 20, 5305-5311. [CrossRef] [PubMed]

37. Kurdi, R.; Táborosi, A.; Zucchi, C.; Pályi, G. Autosolvation: Architecture and Selection of Chiral Conformers in Alkylcobalt Carbonyl Molecular Clocks. Symmetry 2014, 6, 551-565. [CrossRef] 